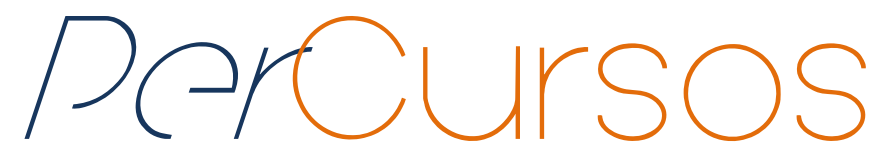

\title{
O contexto de gênero, família e a percepção sobre ser mulher
}

\begin{abstract}
Resumo
O presente trabalho se propõe a apresentar um recorte em torno de uma Tese de Doutorado em 2007, no tocante a em relação a sua percepção de ser mulher no contexto da discriminação de gênero, e inseridas no processo em que as mulheres, estão em sua maioria excluídas da plena vivência como cidadãs, tanto no contexto social como familiar. O projeto do doutorado foi desenvolvido junto a um grupo de alunas das classes populares, de 06 escolas públicas estaduais, em Pernambuco. Para viabilização do referido processo, utilizamos como método de pesquisa o procedimento dialético, buscando tornar visível a problemática da cidadania no universo feminino, frente a uma sociedade patriarcal e androcêntrica, através de um questionário e entrevistas semiestruturadas. Diante do exposto, pode-se perceber que a percepção de ser mulher, aponta que a cidadania feminina - aqui em específico, mas também a dos homens - incorpora os comportamentos que foram e são traçados ao longo da história da humanidade e reforçados pela sociedade e família. Além do que, as mulheres das classes populares têm pouca ou quase nenhuma visibilidade, mobilidade e participação no campo político, social e familiar, encontrando-se ausentes das instâncias decisórias e ideológicas para a efetivação e elaboração de políticas públicas no contexto de gênero.
\end{abstract}

Palavras-chave: Percepção. Mulheres. Gênero. Cidadania.

\section{Walfrido Nunes de Menezes}

Professor/Psicólogo/Coordenador e Doutor em Serviço Social pela

Universidade Federal de Pernambuco - UFPE; Faculdade Estácio do Recife walfrido.menezes@estacio.br

\section{Para citar este artigo:}

MENEZES, Walfrido Nunes de. O contexto de gênero, família e a percepção sobre ser mulher. Revista PerCursos. Florianópolis, v. 14, n.27, jul./dez. 2013. p. 116 - 153.

DOI: $10.5965 / 1984724614272013116$

http: //dx.doi.org/10.5965/1984724614272013116 


\title{
The context of gender, family and perceptions about being
}

\section{a woman}

\begin{abstract}
This paper aims at presenting an outline around a Doctoral Thesis in 2007 in relation to their perception of being a woman in the context of gender discrimination, and included in the process in which women are mostly excluded from a full life as citizens, both in the social and family context. The PhD project was developed with a group of lower income students from 06 public schools in Pernambuco. For the feasibility of this process, we use as a research method the dialectical procedure, seeking to make visible the issue of citizenship in the female universe, in a patriarchal and androcentric society, using a questionnaire and semi-structured interviews. Given the above, one can see that the perception of being a woman, points out that female citizenship - here in particular, but also the male one - incorporates behaviors that were and are traced throughout the history of mankind and reinforced by society and family. In addition, women from the lower classes have little or no visibility, mobility and participation in the political, social and family field, finding themselves absent from decision and ideological instances the achievement and creation of public policies in the context of gender.
\end{abstract}

Keywords: Perception, Women, Gender, Citizenship. 


\section{Introdução}

Pensar sobre a mulher, em relação a sua percepção de ser mulher para além dos tradicionais papéis impostos à mesma ao longo dos anos, tanto no contexto social como familiar, no Brasil, é pertinente, tendo em vista a discrepância entre o que dizem as leis e teorias e a prática de vida do conjunto das mulheres brasileiras. Elas são mães, donas-decasa, trabalhadoras e dinâmicas, mas pouco visíveis na sociedade da qual fazem parte, ainda em sua maioria excluídas da plena vivência como cidadãs ${ }^{1}$ participantes, atuantes e presentes no encaminhamento de suas ações no e para o mundo.

O contexto das classes populares ${ }^{2}$ permeou todo o trabalho, visto que representa a maior parte da população brasileira: a parcela que se encontra alijada e/ou excluída do acesso permanente e com qualidade à saúde, à educação, ao trabalho, à segurança, a uma vida digna, à não violência contra a mulher e à não discriminação de gênero.

De acordo com Tavares e Buarque (2011, p.55), a classe social "é a forma de se estabelecer a divisão da sociedade em grupos, reunindo as pessoas em função do lugar que, cada uma, ocupa no processo de produção de bens e de serviços, e de se definir os iguais e os desiguais, em razão de sua situação econômica."

Segundo Saffioti (2004), o não cumprimento ou a frequente violação dessas práticas promovem a exclusão não apenas econômica, mas também simbólica. Refletindo o modelo socioeconômico, político e cultural em que se organiza a sociedade brasileira neoliberal e androcêntrico. Isto é, "as pessoas que não possuem os bens de produção, não conseguem realizar o acúmulo de capital necessário para ascender socialmente" (TAVARES e BUARQUE, 2011, p.55).

Do ponto de vista econômico, a exclusão é consequência da sociedade de classes, enquanto sob o aspecto simbólico, ela é decorrente da dominação patriarcal e androcêntrica. Diante de tais percepções e visões, estruturamos o presente trabalho, tendo como estrutura básica um recorte de parte de um tópico de nossa pesquisa para o Doutorado em 2002 a 2007, no tocante a sua percepção sobre ser mulher.

\footnotetext{
${ }^{1}$ Embora no mundo de exclusões das classes populares essa invisibilidade também atinja os homens, a intenção neste trabalho foi o estudo em torno da cidadania feminina.

${ }^{2}$ No contexto desta pesquisa, entendemos 'classes populares' como aquelas em que as mulheres vivem inseridas em situações de pobreza e/ou exclusão, provenientes de dificuldades socioeconômicas, e sem acesso às políticas públicas não compensatórias.
} 
Portanto, percebemos que o contexto democrático brasileiro não é vivenciado com a mesma intensidade por todas as cidadãs e cidadãos, uma vez que grande parte dos segmentos sociais não participa na mesma condição de acesso aos direitos e vivências proporcionados pela sociedade. Como apontado por Saffioti (2004), Mézáros (2004), Benevides (1991) e Oliveira (20021999/2005), nas classes populares ocorre mais nitidamente a exclusão de gênero e de classe social. Nelas, as mulheres têm pouca ou quase nenhuma visibilidade e mobilidade no campo político, social e familiar, o que termina promovendo dificuldades ou inviabilizando a vivência plena da cidadania ativa ${ }^{3}$.

Meluci (2001) chama a atenção para o fato de que, na maioria das vezes, as estruturas de subordinação direcionadas e assimiladas penetram na memória das sociedades humanas, levando-as a serem assumidas como naturais. Uma vez assimiladas, implantadas na consciência, fica complexo um rompimento. Mesmo quando as discriminações são reconhecidas pelos outros e surgem propostas de mudanças, o processo já está assimilado e incorporado no cotidiano dos seres humanos.

São processos socialmente construídos, gradativamente acumulados desde a mais tenra infância, que se aprofundam na adolescência e juventude, e se perpetuam ao longo da vida, mesmo quando ocorrem significativas mudanças na sociedade, na família, na escola e promovidas pelos movimentos feministas e as mulheres em geral. A pesquisa mostrou, por exemplo, que hoje as mulheres já sabem e entendem que passam por exclusões e discriminações.

Esse aspecto foi observado durante a nossa pesquisa para a dissertação de mestrado (1999), com adolescentes grávidas, em Caruaru. Embora reclamassem do machismo, para elas isto fazia parte da cultura e da sociedade como um todo. Por exemplo, uma adolescente relatou que estava em casa assistindo ao São João de Caruaru pela televisão e viu o marido "se agarrando" com outras, aos beijos e abraços, mas no final disse: "o importante é que ele não ficou com ela, e sim voltou para casa”.

\footnotetext{
${ }^{3}$ Por 'cidadania ativa' utilizamos o conceito de Benevides (1991, p. 19-20), quando aponta que a mesma supõe a participação popular como possibilidade de criação, transformação e controle sobre o poder, ou os poderes, pois a participação popular é aqui considerada um princípio democrático, e não um receituário político, que pode ser aplicado como medida ou propaganda de um governo, sem continuidade institucional.
} 
Na mesma pesquisa, cerca de $30 \%$ das adolescentes informaram que havia pressão dos homens para transar com as namoradas, o que revela a presença de violência simbólica ${ }^{4}$. Percebe-se, portanto, que no campo simbólico ainda existe o contexto da violência subjetiva, que aparece nitidamente quando as práticas sexistas impõem atitudes sobre as mulheres, as quais ficam sem espaço até mesmo para questionar o comportamento masculino.

Para examinar essas questões, buscamos referências teóricas em livros, periódicos, revistas e na internet. Uma análise minuciosa dessas fontes possibilitou a definição do aporte teórico que se identifica com o processo de trabalho escolhido. Assim, para a reflexão sobre cidadania baseamo-nos na contribuição de Benevides (1991); para a consideração do universo das mulheres, recorremos às concepções de gênero e poder propostas por Saffioti (2004), e Bourdieu (1999).

A cidadania que usamos como categoria de análise é aquela em que os seres humanos estão diretamente contemplados, envolvidos e participantes do processo de construção social e humana, inclusive com acesso aos bens, serviços e lazer, como fatores preponderantes para o desenvolvimento da humanidade. Tal compreensão de cidadania nos levou à aproximação com três autores: Benevides (1991), através de sua concepção ativa, que contempla a participação popular na criação, transformação e controle sobre o poder; Oliveira (2002), no que diz respeito ao princípio de autonomia como autor participante; e Júlio (2000), quando diz ser o sujeito, além de portador de direitos, também protagonista dos mesmos.

As mulheres, no Brasil, apesar de terem hoje maior tempo de permanência na escola do que os homens, como apontado por Rosemberg (2001), ainda não concretizaram na prática ações igualitárias, respeitosas e longe da dominação do masculino. Embora com a maior escolarização, maior participação social e presença das mulheres no mercado de trabalho, as estruturas patriarcais ainda não foram rompidas totalmente, permanecendo fortes elementos discriminatórios e/ou de exclusões econômicas e simbólicas sobre as mesmas.

\footnotetext{
${ }^{4}$ De acordo com Bourdieu (1989), termo que caracteriza a violência não declarada, fruto de relações de poder naturalizadas na cultura, que agem de maneira geral sobre o sujeito, independentemente de sua compreensão.
} 
Já no contexto familiar, podemos perceber que a partir de sua organização verificamos uma visão centrada no patriarcalismo, porém com significativas mudanças, uma vez que "o casamento deixou de ser principalmente um acordo de interesses econômicos para ser uma união afetiva, marcada pela satisfação sexual e emocional" (GIBRAM E PAZ, 2010, p. 461).

Ainda segundo, Gibram e Paz (2010, p. 471)

apesar do trabalho da mulher nunca ter sido valorizado, a sociedade brasileira atribuiu um valor especial às mães como centro emocional e o elemento aglutinador da família. O pai é uma figura socialmente aceita como menos relevante, menos confiável, e menos presente na família.

Por fim, podemos apontar que no desenvolvimento do presente trabalho, estudar as concepções e elaborações de papéis de gênero, no contexto de classe, com o propósito de verificar como as mulheres reelaboram o conceito de cidadania em seu contexto de vida social e familiar, apontou a importância da classe social no processo de construção do sentimento e percepção dos papéis. Para tanto utilizamos um processo metodológico com a aplicação de entrevistas semiestruturadas, e com a análise de conteúdo para os dados obtidos 5 .

Assim, seguindo o procedimento dialético, buscamos tornar visível a problemática da cidadania no universo feminino, por intermédio dos processos contidos nas representações sociais da população. Do ponto de vista social, político, econômico, educacional e cultural, é evidente a existência de uma discriminação de gênero. Todavia, ainda não ficou explícito como isso ocorre e é representado na vivência e compreensão de cada mulher com escolarização, e como esse processo gravita nas representações sociais.

\footnotetext{
${ }^{5} \mathrm{O}$ trabalho foi desenvolvido através de um questionário, com 114 mulheres, e de uma entrevista semiestruturada, com 12 mulheres, dentre as 114, aprovado pelo Comitê de Ética da Universidade Federal de Pernambuco; e teve os nomes das entrevistadas trocados, para preservar a identidade delas.
} 


\section{Conceito de gênero}

O conceito de papéis de gênero refere-se ao conjunto de expectativas sociais sobre os comportamentos 'adequados' e 'claramente' distintos que a pessoa deverá manifestar, conforme o sexo a que pertence. Os gêneros ao longo da história da humanidade, sempre foram pautados por relações que implicam uma constante desigualdade e segmentação entre o feminino e o masculino. Embora essas relações tenham passado por mudanças significativas a partir da segunda metade do século XX, com o avanço dos movimentos feministas, estas ainda não contemplam a totalidade do universo feminino.

Passo a passo, efetivas mudanças começaram a acontecer para as mulheres a partir das décadas de 1950 e 1960, quando o mundo passou por grandes transformações, tais como os movimentos hippie e feminista, a descoberta da pílula e, com isso, a separação entre sexualidade e reprodução. Em decorrência, pequenas conquistas foram afetando e mudando a realidade feminina, como a entrada cada vez maior de mulheres na universidade e no mercado de trabalho. Cabe ressaltar, aqui, a importância e significado que teve, para os movimentos feministas, a publicação, em 1949, do livro $O$ Segundo Sexo, de Simone de Beauvoir, tratando da questão feminina.

Tomando Auad (2006, p. 19) como referência, pode-se dizer que as relações de gênero "do modo como estão organizadas em nossa sociedade, são uma máquina de produzir desigualdades. As visões naturalistas sobre mulheres, meninas, homens e meninos representam travas para a superação dessa situação" Segundo a autora:

Quando começamos a considerar as relações de gênero como socialmente construídas, percebemos que uma série de características consideradas 'naturalmente' femininas ou masculinas corresponde às relações de poder. Essas relações vão ganhando a feição de 'naturais' de tanto praticadas, contadas, repetidas e recontadas (AUAD, 2006, p. 19).

É no bojo dessas relações sociais que se vai construindo a identidade de gênero, construídas ao longo da vida e internalizadas como naturais, no processo de socialização, isto é, "as identidades sociais são construídas, portanto, no âmbito da cultura e da história" (MADUREIRA, 2010, p. 44). Ela começa no nascimento e vai se estruturando na 
infância, adolescência e idade adulta, no trato das relações sociais, familiares e na educação escolar.

Tais estruturas organizaram-se também em torno do sistema econômico, apoiando-se na ideia de propriedade privada, bem como na continuidade da herança, portanto, no patriarcado. Os homens, historicamente, se apropriaram do poder, que lhes concedia o pleno e total direito sobre a mulher e a prole.

Assim, a percepção de gênero é inserida em um modelo de submissão da mulher diante do homem, reflexo de um longo, permanente e exaustivo processo de opressões e condicionamentos sociais. O "sexismo não é somente uma ideologia, reflete, também, uma estrutura de poder, cuja distribuição é muito desigual, em detrimento das mulheres" (SAFFIOTI, 2004, p. 35). Além do mais, "as relações patriarcais, suas hierarquias, sua estrutura de poder contaminam toda a sociedade, o direito patriarcal perpassa não apenas a sociedade civil, mas impregna o Estado" (SAFFIOTI, 2004, p. 54). De acordo com a autora:

Não há, de um lado, a dominação patriarcal e, de outro, a exploração capitalista. Para começar, não existe um processo de dominação separado de outro de exploração. Por esta razão, usa-se, aqui e em outros textos, a expressão dominação-exploração ou exploraçãodominação. (2004, p. 130)

Na visão de Bourdieu o poder é também simbólico, reflete-se em todos os âmbitos da sociedade, gerando desigualdades na maioria das vezes difíceis de serem modificadas. De acordo com esse autor (1998), o poder é um processo invisível, que ocorre onde menos se espera e no mais profundo do ser, isto é, “[...] pode ser exercido com a cumplicidade daqueles que não querem saber que the estão sujeitos ou mesmo o exercem" (BOURDIEU, 1999, p. 8). Dessa forma, o machismo não se organiza unicamente em torno do homem, mas faz parte também do discurso de muitas mulheres. Ele raramente é questionado por grande parte delas. Como apontou Saffioti:

Imbuídas da ideologia que dá cobertura ao patriarcado, mulheres desempenham, com maior ou menor frequência e com mais ou menos rudeza, as funções do patriarca, disciplinando filhos e outras crianças ou 
adolescentes, segundo a lei do pai. Ainda que não sejam cúmplices deste regime, colaboram para alimentá-lo. (2004, p. 102)

Balizado pelo patriarcado, fortalecido pela religião e pelo Estado, o processo androcêntrico e capitalista perpetuou e continua perpetuando atitudes e posturas sexistas, que restringem tanto as mulheres como os homens. Assim, as meninas e os meninos, desde a mais tenra idade, vão incorporando os procedimentos e realizando as interpretações dos papéis sociais de gênero que cada um deve desempenhar em seu meio - já pré-estabelecidos nos seus contextos de vida e apreendidos e internalizados na educação familiar, bem como ampliados e reforçados no processo de socialização e de educação escolar.

Para Strey (2011, p.183), a visão do gênero “como construção cultural e histórica implica tratar com categorias simbólicas, cujas características principais são dar prioridade à interpretação construída em uma dialética entre o dado concreto e o esquema explicativo, $[\ldots]$ "...

Portanto, a identidade de gênero da mulher e do homem incorpora os comportamentos que foram e são traçados ao longo da história da humanidade e reforçados pela sociedade e pela educação escolar, definindo e estruturando os papéis sociais em que cada um dos sexos deverá agir, interagir e expressar sua feminilidade e masculinidade no mundo.

\section{Um breve contexto da família}

A família, seja em qual modelo existente, participa ativamente do processo de socialização, reforçando ou não a discriminatório de gênero, percebido no discurso, na linguagem, no conteúdo, no espaço, nas brincadeiras etc., que são ou não estimuladas desde a infância para com seus filhos, sejam meninos ou sejam meninas. Em geral, as brincadeiras para com o universo feminino tendem como observou Moreno (1999), "as meninas têm liberdade para serem cozinheiras, cabeleireiras, fadas madrinhas, mães que limpam seus filhos, enfermeiras etc., e os meninos são livres para ser índios, ladrões de gado, bandidos, policiais, 'super-homens', tigres ferozes ou qualquer outro elemento da 
fauna agressiva tolerada ou estimulada pelo ambiente (grifo nosso)" (p.32).

Percebe-se, no contexto diário ou escolar uma eterna separação entre as atividades ditas femininas e as ditas masculinas, como se fossem um programa “determinado biologicamente”, e não como processos socialmente construídos, como apontam Strey (2011) e Auad (2006), as crianças, mesmo já apresentando hoje significativas parecerias, ainda reproduzem o contexto familiar, da separação entre as atividades publicas e privadas, isto é, meninos em atividades mais agressivas e as meninas em atividades mais tranquilas.

Assim, os meninos vão incorporando a visão de durões, fortes etc., e não incorporam ou se esquecem do comportamento afetivo, da docilidade - sempre passada pelas mães ou a mulher que os cria -, atitudes naturalmente estimuladas e reforçadas junto às meninas. Já quando maiores, como adolescentes ou adultos, tal processo dificulta compreender a relação de integração entre mulheres e homens; ambos são formados e identificados com e a partir de papéis diferentes, opostos e hierárquicos, e não complementares. Os jogos, as brincadeiras e mesmo as cobranças familiares e escolares, ainda apresentam antigos receios na organização da identidade de gênero, seja masculina ou feminina.

Scott e Cordeiro (2013, p. 134), apontam em pesquisa realizada no interior de Pernambuco que "homens e mulheres no campo concorda que elas têm obrigação de participar numa relação com o parceiro sexual mesmo sem estar com vontade! A sexualidade subserviente é uma arma que subordina a mulher a uma noção de uma hierarquia polarizada entre homens e mulheres".

Inserido nesse contexto, podemos perceber como se organizou e organiza a história da família no Brasil. No país, com a colonização predatória, a vinda dos portugueses estrutura uma ação de depredação, imposição e catequização indígena, rompendo com os costumes primitivos, saudáveis e específicos da cultura local. Além de que assustou os portugueses, a pureza da nudez indígena, frente ao puritanismo da corroa portuguesa, centrada em trações repressivos e castradores da sexualidade humana. Só, por volta do final do século XVI e inicio do XVII, foi consolidado social e politicamente um sentimento de família que estimula o privado, a intimidade, embora na 
estrutura social dos privilegiados.

Por outro lado, os demais grupos sociais, só no século XVIII, "se encaixam neste novo conceito de família" (CHAVES, 1997, p.18). A partir do século XVIII ocorreu a “privatização da família, acompanhada da privatização da propriedade e da apropriação do produto do trabalho" (CHAUI, 1984, p.130).

"Durante o império, o vínculo religioso católico era indissolúvel e determinava o estado conjugal das pessoas. A partir de 1870, de acordo com a lei $n-^{\circ} 1829$, deu-se a organização do registro civil pelo Estado (...). Na República, a lei de 24 de janeiro de 1890 criou o casamento civil, que é independente do religioso e o único a ter validade jurídica e civil" (BERQUÓ, 1998, p.412).

Ocorre então "uma regulamentação da família pelo Estado por meio do casamento civil. Sua proteção é feita pelos Códigos Civil e Penal, e sua manutenção é garantida, também, por meio da escola pública, onde elas passam a compreender que a família é a célula mater da sociedade e do Estado, sem considerar a estrutura e classe, ocultando que as bases da sociedade e do Estado são classes sociais antagônicas" (CHAUI, 1984, p.134).

No país, "as elites no século XIX, estão voltadas para os centros da cultura europeia e o povo era reduzido a uma referência negativa, símbolo do atraso, atribuindose significativo nulo à sua herança cultural não-europeia e negando-se valor à sua criatividade artística" (FURTADO, 1999, p.64).

No Nordeste, a mulher branca no contexto da família patriarcal (chamada sinhazinha) "apresenta o perfil delineado, por Gilberto Freyre, quanto à docilidade e passividade com atitudes voltadas para o interior da casa grande" (NEDER, 1998, p.29).

Com o processo de miscigenação ${ }^{6}$ existente em nosso país, elemento bastante marcado na obra de Gilberto Freyre, "Casa Grande \& Senzala"7 (1963), costumes, amores, ideias e posturas foram sendo incorporados e modificados ao longo dos séculos até o presente momento.

\footnotetext{
${ }^{6}$ A cultura brasileira se estruturou dentro de um processo de miscigenação, isto é, baseado na trilogia étnica e cultural formada pelo: índio, o branco (português) e pelo negro africano.

${ }^{7}$ Ver neste livro o capítulo sobre a sexualidade.
} 
No século XIX, com o projeto republicano, "modernizaram-se, então, as concepções sobre o lugar da mulher nos alicerces da moral familiar e social. Ao contrário da família tradicional, a nova mulher moderna deveria ser educada para desempenhar o papel de mãe (também uma educadora - dos filhos) e de suporte do homem para que este pudesse enfrentar a labuta do trabalho fora de casa" (NEDER, 1998, p. 31).

Pequenas mudanças na estrutura familiar começaram a ocorrer a partir de 1942 quando "foi introduzido no Código Civil o artigo 315, que estabeleceu a separação sem dissolução de vínculos, ou seja, o desquite. Ainda neste mesmo ano, a lei n. ${ }^{\circ} 4529$, de 30 de julho, regulamenta a anulação do casamento (...) e a lei de n. ${ }^{\circ} 6515$, de dezembro de 1977 instituiu o divórcio, permitindo aos divorciados que contraíssem novo matrimônio" (BERQUÓ, 1998, pp. 412 -13).

Nos últimos 30 anos, a sociedade e a família passaram por grandes transformações. Enquanto na década de 50 e 60, o casamento era o ponto central para justificar o relacionamento sexual e o nascimento dos filhos, a partir do fim da década de 60 e inicio da de 70, com os movimentos hippies, a pílula, a música etc., ocorre uma revolução na família, com o movimento feminista, a saída da mulher para a universidade e o trabalho, passando ela a ter controle sobre o corpo.

Nesse contexto, as bases familiares começaram a ser questionadas, principalmente em termos de espaço privado para as mulheres e de público só para os homens. No espaço público a mulher começou a promover várias mudanças sociais, entre elas: a da submissão, da dependência, do machismo, do casamento tradicional etc. O seguinte passo foi desvincular o sexo do casamento, o que possibilitou uma maior liberdade da mulher.

Observamos hoje, entre os jovens, uma "inversão ou negação da moral sexual tradicional e ainda do casamento religioso e civil como modelo de família, negação da procriação como proposta de vida a dois e sim por escolha, questionar a estrutura segmentada dos papéis masculinos e femininos, desejando atração, ternura e amor nas relações..." (CHAUI, 1984, p. 139).

Para Berquó (1998, p. 417), com a qual concordamos, "a transitoriedade que caracteriza essa fase da vida, aliada à percepção da instabilidade do vínculo conjugal de 
seus familiares e amigos, pode levar os jovens a buscar formas de união mais coerentes com seu estilo de vida". Constatamos no Brasil que "no cenário matrimonial, houve um declínio na taxa de nupcialidade legal $^{8}$ entre 1979, quando atingia 7, 83, e em 1994, quando passou a 4, 96, (...) vem ganhando importância no país o número de casamentos não legalizados - a coabitação sem vínculos legais ou união consensual" (BERQUÓ, 1998, pp. 414 - 15). Em pesquisa de Menezes (2002), a relação consensual é o que constatamos na prática, pois apenas duas adolescentes tinham casado formalmente, enquanto que doze outras viviam com o companheiro e seis delas com suas famílias.

Portanto, a família "começa a perder espaço para um modelo monoparental9 (década de 60 a 70) - pai e filhos ou mãe e filhos; embora o modelo nuclear - burguês ainda seja o referendado no processo de socialização, seja nos grupos ricos como nos pobres" (CHAUI, 1984, p. 130). Assim, estamos no século XX e posteriormente no XXI, com novas formas de organizações sociais, que vão se estruturando no universo social, em torno da família.

A partir dos novos modelos e papéis diferenciados da família, constatou-se hoje, uma crise acentuada em relação ao patriarcalismo, que segundo Castells (1999), pode ser vista combinando quatro elementos: transformação da economia e do mercado de trabalho, associada à abertura de oportunidades para as mulheres no campo da educação; transformações tecnológicas ocorridas na biologia, farmacologia e medicina, proporcionando controle cada vez maior sobre a gravidez e a reprodução humanas; fragmentação do patriarcalismo, tendo como pano de fundo o movimento feminista no contexto de transformações econômicas e tecnológicas; a rápida difusão de ideias em uma cultura globalizada, em um mundo interligado por onde pessoas e experiências passam e se misturam, tecendo rapidamente uma imensa colcha de retalhos formada por vozes femininas, estendendo-se sobre quase todo o planeta.

Acrescentamos ainda a crise do mercado de trabalho que tira muitos homens do emprego, enquanto torna-se muitas vezes mais fácil para as mulheres de classes sociais populares encontrarem trabalho. Diante de sua educação machista, ela sempre aprendeu as tarefas domésticas, o que proporciona a possibilidade de trabalho como doméstica,

\footnotetext{
${ }^{8}$ Número de casamentos legalizados por mil pessoas.

${ }^{9}$ Monoparental: família composta por mãe ou pai - chefe de família - e filho (os).
} 
arrumadeira, lavadeira etc. Ela passa, então, em muitos casos, a ser provedora da família, papel que tradicionalmente cabia ao homem.

\section{Percepção sobre ser mulher}

A partir do contexto teórico acima mencionado, podemos entender o contexto de organização das relações de gênero, no contexto familiar e social. Mediante, tais aspectos a partir de pesquisa desenvolvida por Menezes (2011), podemos compreender tal organização através da estrutura de percepção de ser mulher.

A percepção de ser mulher, sobre si mesma, o outro e o mundo dos seus direitos, em prol de uma cidadania ativa, apareceu em várias etapas da pesquisa apontada acima, quando elas foram unânimes ao afirmar que ser mulher é algo bom ou ótimo, entretanto, reconhecem a existência de fortes diferenças entre elas e os homens, na medida em que eles seriam menos discriminados e teriam maior participação social, enfim, teriam mais direitos.

Assim, a pesquisa apresentou dados bastante significativos. Por um lado, os elementos de reprodução de uma cidadania feminina fragilizada e longe dos objetivos propostos da cidadania ativa; e, por outro lado, os elementos novos oriundos das recentes reflexões adotadas pelas mulheres, diante das transformações sociais e feministas ao longo dos séculos, que possibilitaram transformações, mas também recuos provenientes das distorções sociais da exclusão sobre as mulheres.

Nos depoimentos é possível verificar que a mulher, mesmo percebendo e vivenciando novas possibilidades, ainda está presa a antigos comportamentos. Diante de tais processos, concordamos com Lipman (2001, p. 369), ao afirmar que, "para muitas pessoas, convicções e atitudes preconceituosas encontram-se instaladas no íntimo; a ideia de abandonar estas convicções e atitudes faz com que assumam uma postura extremamente defensiva."

Entretanto, mesmo considerando a mulher frágil, elas apontam que "ela tem força, garra e não existem obstáculos". Além do mais, consideram que as mulheres são “mais responsáveis do que o homem e também são brabas", como, por exemplo, quando 
se mexe com um filho dela. A docilidade feminina foi também questionada, ao se considerar que isto "não significa ser dona de casa, pois a mulher pode vir a trabalhar" (Fernanda B., 20 anos).

Em geral elas concordam que existe uma hierarquia, estando a mulher abaixo do homem; parece ter sido criado infelizmente este vínculo, pois “o pensamento do povo é assim" (Simone, 17 anos). Percebe-se na pesquisa que as mulheres ainda vivem em um contexto precário em termos de seus direitos, como se observa nos depoimentos a seguir:

Apesar de a mulher ter direito a dar à luz, emprego, casar, ter uma vida digna na sociedade, isto é apenas visto como o ideal. (Natali, 20 anos)

Eu acho que é o que acontece ser mãe e ter que ficar em casa. Porque quando a mulher casa e tem filhos é o que acontece. (Helena, 19 anos)

Diante do exposto, percebe-se que um mito gradativamente construído, aqui o mito do amor materno, se estrutura a partir de uma visão incorporada e internalizada pelas mulheres. Homens e mulheres forjados nessas concepções tendem a reproduzi-las nas gerações subsequentes, como ainda aparece com muita força, nos dois depoimentos abaixo:

Ser mulher foi obra divina de termos oportunidades de fazer várias coisas, por exemplo, ser mãe. É uma coisa maravilhosa, tem privilégios, pois pode ser mãe, isto é o que Deus deu para mim. (Nikita, 20 anos)

Mesmo não se tratando aqui do direito das mulheres quererem ter filhos, o que chama a atenção é o grande enaltecimento da maternidade e as limitações postas em torno disso. O mito materno apareceu na pesquisa de campo anteriormente realizada, nesta mesma cidade de Caruaru; junto a vinte adolescentes do sexo feminino (MENEZES, 2002), o que mobilizou inclusive o aprofundamento dessa questão de gênero, visto que as adolescentes da pesquisa anterior disseram ser algo normal, "uma coisa de mulher, da natureza feminina", e abria mão de tudo pelo filho, aparecendo, claramente, a questão da maternidade no grupo como um todo. 
Tais concepções apontadas acima, nos direcionam para uma leitura de modelos familiares, reprodutores dos antigos papéis apontadas para com o universo feminino, dos cuidados com o outro, no caso o filho.

Isso também é reforçado nas respostas à pergunta: o que é bom e legal, e o que é ruim na mulher? Tanto aparece que o bom seria o dar a vida a um ser humano, a uma criança, sem maiores comentários, como também aparece a maternagem como o bom, mas acompanhada do ruim, que é a ausência do pai da criança, como se pode constatar nos depoimentos abaixo:

O bom e legal é ser mãe. É maravilhoso apesar das dificuldades que tem em cuidar de um filho sozinha. (Maria, 33 anos)

A mulher sofre quando tem filhos, tem que cuidar, o homem não quer cuidar, quando a criança chora o homem sai. (Quíria, 25 anos)

Como a pergunta era voltada para os aspectos em geral do que é ser mulher, notase como ainda está internalizada a visão da maternagem e dos antigos papéis familiares apontados no contexto feminino para com o seu universo, que é evidenciada, ao mesmo tempo em que não são nem vislumbrados outros caminhos além desse. Quando elas chegam a reclamar é apenas de ter que cuidar dos filhos sozinhas. Embora isso seja pouco, merece destaque, pois antes, em geral, as mulheres nem questionavam (MENEZES, 2002).

O importante, neste momento, é registrar a questão em torno da maternagem na pesquisa. Aparece no depoimento abaixo a antiga e tradicional concepção do universo feminino, em resposta à pergunta: o que você pensa disso?

Eu acho que é o que acontece ser mãe é ter que ficar em casa. Porque quando a mulher casa e tem filhos é o que acontece. (Heloísa, 19 anos)

Heloísa, neste depoimento, expressa o que já foi evidenciado na pesquisa, da presença feminina como mãe; ela acredita na suposta 'naturalidade' do processo. A pretensão, aqui, é apontar que as mulheres hoje, em geral, oscilam entre o tradicional e o 
moderno. Não há uma crítica à maternagem, elas apenas criticam a ausência do pai da criança, ainda corriqueiramente visto no espaço público. Enfim, essas posições acima mencionadas refletem que o homem tudo pode e está isento de maiores responsabilidades perante as mulheres.

Os mitos são modelos "incorporados" e "naturalizados" pelo contexto social. No imaginário social, o que conta é o fato de ser mãe, esse é o papel que toda mulher tem que cumprir. Embora possam existir discriminações e exclusões em relação às mulheres, “mãe é mãe, a isto ninguém questiona”. Tal colocação não é vista como discriminação por elas. Chama a atenção o fato de que, em geral, as pesquisadas apontam isso como uma característica inata da mulher. Elas devem cumprir o seu 'destino' de ser mãe e esposa, condição para que se sintam femininas e valorizadas no meio social, isto é, os antigos papéis impostos culturalmente para o modelo de família androcêntrica.

São limitações que a vida social lhes impõe, como Rosemberg (1994) reforça, pois tais tarefas ditas 'femininas' no lar representam menor liberdade para as mulheres, diante do extremo cansaço diário, o que impede ou dificulta a sua disponibilidade para realizar atividades fora de casa, que comprometam seu papel no espaço privado. Assim, diante da maternagem e da vida doméstica, são poucos os espaços de vivência do processo de cidadania, pelas limitações que tais tarefas acarretam para elas. Natália (17 anos) coloca que a mulher é muito cobrada quando estuda e trabalha dentro de casa: "tem que ser $100 \%$ dentro de casa, cuidar da casa".

Mas, por outro lado, elas também pontuam avanços significativos. Reconhecem que a discriminação e a exclusão são oriundas da sua condição de mulher, e acreditam que mudanças estão ocorrendo no sentido da construção da cidadania. É importante ressaltar que as mulheres têm a noção de cidadania, mas admitem, entretanto, a necessidade de ocorrer mudanças de atitudes e comportamentos para que isso seja efetivado no cotidiano.

No sentido mais amplo, que envolve direta ou indiretamente os vários direitos das mulheres, observam-se avanços e recuos nas questões femininas, mas nada tão forte como antigamente, depois das mudanças ocorridas a partir das décadas de 1960 e 1970, por intermédio dos movimentos feministas. 
De modo geral, na pesquisa (MENEZES, 2011), as mulheres reconhecem que possuem todos os direitos - de moradia, de lazer, de respeito, de ir e vir, de estudar e trabalhar etc. -, mas que na prática ainda existe "a falta de respeito pela mulher" ou a maioria das pessoas "discriminam a mesma”. Maria (33 anos) expressa nitidamente que a mulher tem o direito "de falar o que está sentindo, de lutar pelo seu ideal, porque a mulher é um ser humano como outro qualquer." Porém, outras entrevistadas ressaltam:

Ela não tem pelas proibições e pelo desrespeito que lhe cai no contexto social. (Natali, 20 anos)

A gente é às vezes discriminada, em não poder fazer tudo. (Andreza, 20 anos)

Nas respostas constantes percebem-se os antigos papéis postos em evidência, quando elas apontam as principais qualidades da mulher, uma vez que dentre as mais citadas aparecem antigas concepções atribuídas ao universo feminino, tais como: educada, ser mãe, fiel, carinhosa, dedicada, dona-de-casa, sincera, amiga, companheira, compreensiva, romântica, frágil, responsável, sensível, vaidosa e forte. Isto é, no mínimo, contraditório, pois diante de tantas exigências o que se espera é uma perfeição impossível.

Assim, nas respostas sobre "as qualidades da mulher", ainda prevalecem os antigos conceitos de dona-de-casa e mãe. Isso se percebe no discurso da sociedade, de que o homem tudo pode e não tem que se preocupar com o que pensa e sente sua companheira; enquanto a mulher, submissa, tem que ficar em casa, esperando, feliz da vida.

Na pesquisa, quando perguntadas como elas achavam que as pessoas as viam como mulheres, as respostas mais frequentes foram: inferior ao homem, dependente, frágil, dona-de-casa, objeto de uso, incapaz, com preconceito e sensível. Como característica oposta foi citada apenas batalhadora, a qual, mesmo assim, aparece na sétima posição em relação às demais.

Permanecendo assim, uma perspectiva, da mulher ser frágil, mais dócil do que o homem. Porém, algumas colocações já expõem uma certa reflexão por parte das 
mulheres, como quando apontam os limites do homem em ser paciente. Embora elas ressaltem a existência do machismo, os valores internalizados dificultam a percepção de tais processos como socialmente construídos, como mostram os depoimentos abaixo:

Porque ainda existe o machismo e, também, por ela ser mais frágil, que já é cientificamente comprovado. (Simone, 17 anos)

Ainda é atribuída às qualidades da mulher como sendo mais carinhosas e mais compreensivas em relação ao homem.

Na verdade, são estereótipos, preconceitos e papéis sobre o universo feminino e masculino, que são socialmente construídos e produzidos ao longo dos anos, implicando comportamentos dissociáveis e confusos nas relações entre os seres humanos, independentemente de idade. Segundo Jodelet (1999, p. 59), os estereótipos "são esquemas que concernem especificamente aos atributos pessoais que caracterizam os membros de um determinado grupo ou de uma categoria social dada".

Outro estereótipo comum apontado pelas mulheres participantes da pesquisa é o “medo", mas ninguém nasce com medo, ele é socialmente construído e vai sendo gradativamente incorporado pelo sujeito, como algo que lhe pertence. Observem-se os depoimentos:

Pois a mulher fica com temor de poder acontecer algo, aí, mesmo contra, obedece. (Heloísa, 19 anos)

O medo é porque o homem pode achar ruim se ela der uma opinião sua e ele não aceitar. (Quíria, 25 anos)

As mulheres agem assim para não haver confusão, aceitam por uma parte o que eles querem evitando confusão e conflitos com a família. Para não haver confusão a mulher aceita o que o marido quer. (Carla, 18 anos)

Mesmo quando a mulher adota tais posturas "por respeito ou falta de opinião", ela vê tais atitudes como uma cobrança que termina por afetar sua autoestima, o que também é evidenciado por Fernanda B. (20 anos), quando diz: “As mulheres aceitam as decisões por respeito, obediência e por amor, porque a partir do momento que você ama, 
você só quer fazer o bem." Nota-se também, nesse depoimento, a questão do amor justificando tudo na vida, mas não como desenvolvimento e crescimento, conforme apontado em Menezes (2002); na verdade, é apenas um "amor" entendido como resignação de sua condição de mulher.

Diante disso, as mulheres ficam perdidas e à mercê de atitudes impensadas, o que acarreta problemas ao longo da sua vida; assumir o medo não trará uma boa relação, muito pelo contrário, essa será fragmentada, distorcida e sofrerá ruptura mais facilmente, diante de qualquer conflito e pela baixa autoestima e falta de autonomia. Assim, as mulheres, com base nos estereótipos culturais da docilidade e meiguice, têm que se apresentar como "inseguras e medrosas" para representar um papel que a sociedade lhes cobra.

A identidade social feminina em geral direciona-se para o atendimento ao outro e não a si própria, através dos modelos pré-estabelecidos que vão sendo incorporados e internalizados pela menina, com relação à maternagem e às atividades domésticas. Na maioria das residências das classes populares é comum as crianças meninas arrumarem a casa e cuidarem desde cedo dos mais novos - irmãs ou irmãos.

Esse processo está tão bem internalizado pelas mulheres que, tanto no questionário como na entrevista, estas atividades aparecem como funções 'naturais' do universo feminino.

Da casa cuida a mulher, principalmente quando é casada e tem filhos; é através dela que ocorre o processo de socialização da criança. Assim, como não reproduzir isso para as filhas e os filhos?

Nesse sentido, pode-se apontar que as sociedades ocidentais, patriarcais e capitalistas, para excluir de uma maneira mais efetiva as mulheres do processo de socialização, tomaram como referências as ciências "naturais", a Medicina, a partir do século XVIII e, posteriormente, a Psicologia positivista, em que se associa o sexo biológico, masculino e feminino, ao corpo, gerando uma dicotomia. Assim a gravidez, gestação, parto e amamentação dotavam a mulher de um papel natural de docilidade e delicadeza, além do amor materno, visto como algo “indispensável” para o desenvolvimento físico-emocional das(os) filhas(os). Transmite-se para as mulheres o 
papel de guardiãs do afeto e da moral na família, associando-as a um corpo ligado à reprodução e à maternidade.

Já a identidade masculina se organiza como viril, corajosa, forte, provedora e protetora da família. Na concepção arbitrária do biológico, o modelo social volta-se para a masculinidade - essa também uma outra forma de discriminação. Assim, tomando Bourdieu (1999) como referência, pode-se dizer que isso é uma falsa legitimidade, decorrente da natureza biológica, que é, ela própria, uma construção social naturalizada.

Por sua vez, Saffioti (1992) imputa tal processo biológico como um argumento que carece de fundamentos científicos. Delicadeza, proteção, afetividade, carinho não podem ser utilizados como sinônimos de fragilidade biológica, mas sim como capacidades e qualidades humanas de primeira grandeza, tanto para a mulher, quanto para o homem, o qual tem seus movimentos emotivos castrados durante o seu crescimento.

Assim, a identidade de gênero é socialmente construída ao longo de todo um processo de socialização, iniciando-se no espaço familiar e ampliando-se e perpetuandose no campo social e no sistema escolar. Portanto, os modelos anteriormente apontados colaboraram e colaboram para que as identidades de gênero sejam internalizadas.

[...] em etapas de nossa infância em que não temos desenvolvido ainda nenhum mecanismo de crítica que permita colocá-las sob suspeita. Uma vez instaladas, tornam-se de difícil modificação, precisamente porque ignoramos sua existência e porque esquecemos completamente a forma pela qual as adquirimos. (MORENO, 1999, p. 67-68)

Podemos acrescentar que a identidade social de gênero vai, gradativamente, promovendo uma constante discriminação, tanto em relação à mulher, quando a ela são atribuídas triplas jornadas de trabalho - como dona-de-casa, mãe e nas atividades exercidas no espaço público -, quanto ao homem, quando lhe é cobrado um papel de superioridade, negando uma relação de igualdade e equidade entre ambos, e lhes são vetadas expressões de fragilidade e de inseguranças.

Todo esse processo tem início com o nascimento e vai, gradativamente, sendo organizando e assimilado, tanto pelas meninas quanto pelos meninos, em pequenas etapas, de acordo com o processo de desenvolvimento humano. O campo emocional está 
ligado à autopercepção que o indivíduo tem de pertencer ao sexo feminino ou masculino, isto é, o sentimento que cada pessoa tem de ser homem ou mulher, com base no sexo genital; é a primeira identificação do indivíduo como pessoa e elemento determinante para a sua identidade.

Quando menina é comum às pessoas se referirem a ela como: 'lindinha', 'fofinha', 'gracinha', etc., palavras muito ligadas aos aspectos amorosos, da meiguice e sempre associados às mulheres. E quando menino, os termos tomam outra direção: 'que menino forte', 'que menino esperto', 'quando crescer vai ser igualzinho ao pai'; são atributos linguísticos que, em geral, estão associados à firmeza, força etc.

Saffioti (1992) argumenta que não se negam algumas características diferentes entre mulheres e homens. Por exemplo, na maioria das vezes, a tipologia do homem é mais forte e maior do que a de grande parte das mulheres no Brasil, porém, quando há referência a uma fragilidade, que é, por exemplo, um infarto, já ocorre muito mais frequentemente nos homens, tendo em vista que os hormônios femininos são defensores naturais para as coronárias delas. E essa, sim, é uma construção biológica real que poderia levar a considerar a mulher, portanto, o sexo mais forte. Diferente é toda a humanidade, mas nem por isso as pessoas são desiguais, mas sim complementares.

Sob uma conotação biológica, a discriminação encontra apoio e embasamento na lei, pois no caso específico do Brasil o Código Civil de 1916 continha várias regras discriminatórias contra a mulher. Este ciclo discriminatório só foi rompido, em grande parte, no novo código Civil que entrou em vigor em 2003, colocando a mulher e o homem em igualdade, pelo menos na Lei.

Por outro lado, podemos apontar que, o processo de identidade vai se organizando de forma que quase nunca se percebe que é nas relações sociais que a mesma se forja, estabelecendo normas de conduta para as mulheres e para os homens, por meio das roupas, posturas, atitudes, linguagem, etc. E, assim, esse poder se mantém, sustenta e reproduz a identidade de gênero de maneira segregacionista e excluidora da igualdade e equidade ${ }^{10}$.

\footnotetext{
${ }^{10}$ Equidades seria a "possibilidade de as diferenças serem manifestadas e respeitadas, sem discriminação; condição que favorece o combate das práticas de subordinação ou preconceito em relação às diferenças de gênero, políticas, étnicas, religiosas, culturais, de minorias, etc." (SPOSATI, 1977, p. 36).
} 
Menezes (2011) aponta também em sua pesquisa, que as maiorias das 114 mulheres apontaram que se sentira excluída em alguma situação na vida. Assim, 60 delas (53\%) responderam que já tinham vivido a exclusão, enquanto $45(39 \%)$ responderam que não e 9 (8\%) não responderam. Nas respostas dadas, aparecem as explicações: "sim, por ser mulher”; “quando engravidei”; "quando se fala em política”.

A questão da exclusão social é bastante ampla por envolver aspectos ligados ao econômico (pobreza), ao gênero, às minorias, ao simbólico; o que implica o afastamento de um grande contingente de indivíduos do processo de "pertencimento" a uma dada sociedade. Como disse Xiberras, o processo

parece residir na ruptura dos laços que ela provoca, diretamente ou a longo prazo. Ruptura do laço social, mas também do laço simbólico que liga normalmente qualquer indivíduo a sua sociedade. Excluído de uma esfera do social, o sujeito rompeu os laços que o seguravam junto a outros, mas também das representações que lhes eram comuns. (1996, p. 28)

É com base nisso que Nascimento (1994) aponta que o processo de exclusão social impede o ingresso das classes populares na esfera da igualdade, promovendo uma ruptura dos sujeitos e vínculos sociais no contexto mais amplo da vivência do processo de cidadania.

Na visão das mulheres pesquisadas (MENEZES, 2011) existe a exclusão quando se refere a aspectos sociais, e discriminação quando diz respeito ao aspecto pessoal. Diferentemente da exclusão, apenas 35 delas (31\%) responderam que já tinham sofrido discriminação, enquanto 78 (68\%) responderam que não; e uma deixou de responder. Observa-se, com esse resultado, que no geral a mulher não se percebe como alvo de discriminação, como pode ser visualizado no gráfico seguinte.

Portanto, estas situações são ainda confusas, já que elas em sua maioria se sentiram excluídas, mas não discriminadas. Embora 78 mulheres tenham respondido que não se sentiram discriminadas, em nenhum dos questionários foi incluída uma explicação para esse ‘não'. Já as mulheres que responderam "sim” colocaram em suas respostas as internalizações discriminatórias: 
Sim. Meu irmão tem mais direito (de sair, por exemplo). Sim. Por causa de preconceito de que "isso não é coisa de mulher".

É interessante observar que aquelas que disseram ter sido discriminada refletiram a questão relacionada à exclusão de gênero, pois expressaram o que pode ou não a mulher fazer, em relação ao que os homens podem como também mostram os depoimentos abaixo:

Sim. O homem pode ficar com quantas mulheres quiser, se a mulher fizer isso já é discriminada. Sim. Quando homens acham e dizem que não somos capazes de realizar outras atividades além das domésticas.

Por outro lado, quando se analisam os resultados das entrevistas, verifica-se que a maioria quase absoluta das mulheres (11) respondeu que já tinha passado por discriminações. Quanto ao aspecto da discriminação afetar suas vidas, elas foram unânimes em dizer que sim e, embora não soubessem explicitar como isto as afetava, disseram que mexia com a sua autoestima. Os dois depoimentos a seguir exemplificam bem esse processo:

É um sentimento de não servir para mais nada. É horrível, a gente se sente diminuída, sente-se uma pessoa lá embaixo, principalmente se você é casada. (Nikita, 20 anos)

Pode, porque ao ser discriminada eu vou me sentir lá embaixo, não serve para nada. Pode mudar minha mente. (Evalyn, 21 anos)

Os motivos para uma mulher ser discriminada variam, tanto podendo ter como eixo a questão moral, como a de não ser digna, de não se valorizar: "por usar roupas curtas e sair com pessoas diferentes", ou por ser "muito atirada" - elementos apontados por elas como causa de discriminação. Por outro lado, elas próprias colocam que embora “todas tenham direito é preciso saber o limite", voltando à questão do comportamento público da mulher, o cuidado que se deve ter nas roupas, na fala, etc. De um modo geral, é nítida a questão do respeito e da moral que se deve ter diante da sociedade. 
Assim, a discriminação termina produzindo "nas meninas um sentimento coletivo de inferioridade que as situa em considerável desvantagem diante do homem e as aproxima da ideia de que as ações das mulheres têm tão pouco valor, que não podem influenciar no desenvolvimento da História." (MORENO, 1999, p. 75)

Tal fragmentação da autoestima acaba por resultar em um processo de pouca valorização de si mesma, produzindo mal-estar, angústias e falta de perspectiva, gerando inseguranças e frustrações, que levam as mulheres à dependência e a não criarem projetos de vida mais amplos.

Tais características refletem a estrutura patriarcal característica da sociedade, que ainda é determinante na cultura. Discriminações internalizadas terminam por fragilizar os seres humanos, e com isso ocorre à assimilação da impossibilidade de mudança, as concepções discriminatórias e a desigualdades com as mulheres, o que fragiliza seus movimentos.

Nesse sentido, observa-se no grupo estudado uma preocupação no que concerne a lidar com a discriminação e o desrespeito em relação a si mesma, mas sem uma atitude de maior confronto, já que a maior parte das mulheres expressou que "o melhor é ignorar ou sair das discussões". Em poucas situações apareceu a ideia de se contrapor ao homem. Mesmo uma entrevistada que se queixou verbalmente da violência dos homens para com elas acha que "não há o que fazer a não ser conversar". Assim, nem mesmo essa mulher apresentou a questão de maneira mais profunda, em termos de ter direito a se defender da violência, denunciando o homem.

Lipman (1995) diz que os preconceitos são atitudes e comportamentos injustos, tendenciosos e intolerantes, adotados por um grupo social, que existem independentemente de serem ou não verdadeiros e de se manifestarem em atos, como ocorre, por exemplo, nas relações de dominação-subordinação-exploração que se constituem no patriarcado, relações de poder que se escondem e se camuflam atrás dos preconceitos.

Saffioti (1992) já evidenciava que os preconceitos são atitudes perversas da sociedade, uma vez que até mesmo as mulheres que trabalham e produzem mais do que os homens, como as trabalhadoras rurais - na enxada -, se consideram inferiores a eles; 
são, assim, relações internalizadas dentro da cultura androcêntrica.

Uma vez instalado, o preconceito fica incorporado no imaginário social e na compreensão pessoal e interna das mulheres e em suas representações, gerando atitudes de discriminação, exclusão, intolerância, etc., que forjam uma sociedade estratificada. Embora não passem de 'pseudoconceitos', como se pode constatar nos relatos históricos sobre períodos de guerra, quando os homens foram para frente de batalha e as mulheres assumiram suas funções, as quais, antes da guerra, não eram consideradas atividades que a mulher pudesse realizar, diante de sua suposta "inferioridade", atribuída pelo universo masculino.

Podemos observar isso nos depoimentos da pesquisa, no que se refere à discriminação quanto ao trabalho feminino:

A discriminação ocorre para alguns tipos de trabalhos considerados como sendo de homens e não de mulheres. Quando os homens acham e dizem que não somos capazes de realizar outras atividades além das domésticas. A mulher é humilhada na sociedade e no trabalho. (Simone, 17 anos)

A mulher não tem liberdade de expressão, muitas vezes não pode fazer determinado trabalho, outras não podem assumir alguns cargos. (Natali, 20 anos)

Parece que avanços e recuos são as marcas registradas na atualidade em relação à discriminação e ao poder realizar as coisas. Observa-se uma percepção confusa, fruto de todo um processo internalizado que gera acomodações. Assim, ao mesmo tempo em que elas apontam os limites impostos, também assumem alguns desses limites como verdadeiros, conforme mostram os depoimentos a seguir:

O limite vem porque a mulher não pode realizar tudo, como precisar do homem para pegar o pesado. (Nikita, 20 anos)

A mulher não pode tudo, tem coisas que só o homem pode trabalhar, como por exemplo, o trabalho de pedreiro que não dá para mulher fazer. (Carla, 18 anos) 
Atividades de “carregar peso", "trabalho de pedreiro”, etc., ainda são vistas como inadequadas para as mulheres. Chama-se a atenção para a força física masculina, embora isso não passe de discurso machista internalizado pelas mulheres, mesmo que se constate que na construção civil a predominância seja do sexo masculino. Não é possível reconhecer isto como natural, uma vez que para ser pedreira basta que a mulher tenha sido estimulada desde cedo para bem desempenhar tal tarefa; ademais, peso se carrega, em geral, nos carros de mão ou nos elevadores existentes na construção. Tal ponto de vista preconceituoso, assimilado desde a mais tenra idade, é idêntico a outros mais corriqueiros, de que a mulher não pode dirigir táxi, ônibus, caminhão etc.

Os depoimentos mostram que a mulher tem uma visão pouco favorável em relação a si mesma, pois as condições mínimas de vida, além da falta de estímulos sociais, ainda pesam na discriminação de gênero e com isso ocorre uma desvalorização da mulher. Na sociedade, os homens possuem mais oportunidades de trabalho, pois há funções que os homens podem realizar e a mulher não. Uma das participantes da pesquisa revela a situação em que se sente discriminada: "Quando falo em fazer concursos para a polícia".

No momento, a mudança por elas apontada ocorre em torno de poder trabalhar fora de casa, evidenciando uma diferença entre o passado e o presente, quando dizem que "embora sejam discriminadas para certos trabalhos elas já têm uma maior liberdade, já podem trabalhar".

Assim, tais condicionamentos ainda aparecem em pleno século XXI, na pesquisa de campo. O que se percebe, nitidamente, nas entrevistas com as mulheres, é que, mesmo elas tendo mais participação hoje na sociedade, com maior conhecimento e escolaridade, ainda se veem na posição de ceder mais, como se pode constatar nos próximos depoimentos:

Realmente a mulher cede mais porque se acha inferior. Eu acho que a mulher mesmo se diminui.Ela quebrou muitas barreiras [...] você não é mais escrava, mas até hoje existe a discriminação.

Percebem-se, neste sentido, as internalizações existentes no universo feminino, que ainda limitam seus espaços no cotidiano. Por outro lado, é interessante observar que 
mesmo assim elas já demonstram o entendimento de ter direitos, embora ainda apontem a dificuldade de tê-los na prática, diante dos obstáculos que são encontrados ao longo do processo. Uma delas expressa a necessidade de "a mulher ser verdadeiramente respeitada por ser mulher".

Somados aos processos discriminatórios, aparecem os limites claros da submissão, pois, em situações de desrespeito em relação a si mesmas, não revelam uma atitude de maior confronto, de revidar ou se contrapor ao homem, colocando que o melhor é ignorar ou sair das discussões.

\section{É melhor baixar a cabeça e sair. (Carla, 18)}

Porque na nossa sociedade a mulher é sempre vista como um ser inferior ao homem. Porque ainda há muitos preconceitos com a mulher.

Não é difícil que mesmo a mulher que tem consciência de sua situação de exclusão termine por assumir tal discriminação, já que foi educada ao longo da sua vida para “sofrer”, “ser a eterna vítima”, “sofrer em silêncio”, isto é, há um 'masoquismo' internalizado, que aparece nos sentimentos, pensamentos, falas, atitudes.

Quando questionada por que muitas mulheres aceitam a decisão tomada pelos homens, Fernanda Vieira (19 anos) responde: “Porque já é uma tradição, os homens prevalecem sobre as mulheres.” Mas tanto ela quanto Maria (33 anos) chamam a atenção de que a culpa é das próprias mulheres, quando dizem que as pessoas não fazem questão de integrar o novo, e sim as tradições. Natali (20 anos) diz que "algumas mulheres são fracas, não têm coragem de enfrentar, de tomar uma decisão (falta coragem) de se contrapor aos homens, outras não."

Embora apresentem uma maior conscientização da estrutura patriarcal a que estão submetidas, as entrevistadas acabam reproduzindo a trajetória da mulher dependente do homem e, portanto, sem autonomia para reivindicar seu espaço, como se pode constatar nos depoimentos que se seguem:

O homem pode mais sair e chegar a hora que quiser e a mulher, se não chegar cedo é considerada mulher da vida e não pode sair e o homem pode tudo. (Nikita, 20 anos) 
A mulher, é discriminada, tem menos liberdade. Se ela for muito solta (liberal) vai prejudicar a si mesma, pois as pessoas criticam ela. (Fernanda $B, 20$ anos)

Não é legal ir para todos os lugares, por exemplo, ir no jogo, ela não se sentiria bem e em bares que é mais adequado para homens. A mulher vai por causa dos homens que chamam, mas não é o local (bar) adequado para mulher. (Carla, 18 anos)

Mais uma vez voltamos à questão do poder fazer as coisas, mas com certos limites, pois é necessário 'se dar o respeito perante si e os outros', uma vez que a mulher é considerada mais sensível e está exposta aos comentários da sociedade. No último depoimento citado, ainda fica claro que é a própria mulher que assume esta diferença.

Nas relações estabelecidas nesse processo, percebe-se o longo e tortuoso caminho que o universo feminino carrega de subordinação e humilhação, que normalmente são assumidas simbolicamente. De acordo com Bourdieu:

As próprias mulheres aplicam a toda a realidade e, particularmente, às relações de poder em que se veem envolvidas esquemas de pensamento que são produto da incorporação dessas relações de poder e que se expressam nas oposições fundantes da ordem simbólica. (1999, p. 45)

No que se refere particularmente à relação com os homens, as mulheres que participaram da pesquisa apontam que eles são muito machistas, tanto no sentido amplo como especificamente no casamento: "O marido impõe à mulher o limite de não poder ir para todos os lugares, também de não poder trabalhar e nem mesmo continuar a estudar." Esse depoimento reflete a concepção androcêntrica e até mesmo colonial da sociedade. Mesmo a mulher tendo o direito de estudar, torna-se difícil exercê-lo quando é casada, porque os companheiros não querem assumir nenhum compromisso com a casa e os cuidados com os filhos, como revela Quíria (25 anos): “O homem sai de casa quando a criança começa a chorar."

Além disto, de acordo com os dados dos Indicadores Sociais do IBGE (2003), a existência de filhos - e a consequente responsabilidade por seu cuidado e manutenção se constitui em mais um fator de dificuldade para a inserção da mulher no mercado de 
trabalho e/ou continuidade de seus estudos. E segundo os Indicadores de 2001, entre as que têm entre 25 e 49 anos, por exemplo, 82,8\% possuem pelo menos um filho.

Temos aqui dois aspectos preocupantes, tendo em vista que o trabalho promove uma perspectiva mais fortalecida do ser humano e os estudos possibilitam o crescimento e o desenvolvimento pessoal. Sendo privada desses direitos ou sofrendo obstáculos para exercê-los, a mulher tem reduzidas suas possibilidades de realização pessoal e de ampliação da autoestima.

Nos depoimentos estão sempre presentes as questões da maternagem e do cuidado da casa, que ainda prevalecem como sendo atribuições exclusivas das mulheres, mesmo quando elas questionam e lamentam, como Fernanda (19 anos): "mas não é para ser, infelizmente". Aqui aparece nitidamente a questão machista e a discriminação existente sobre as mulheres, pois no depoimento está implícita a reflexão de que "não deveria ser assim”, todavia, “infelizmente, é assim mesmo”.

O que termina por resultar no que Lipman (1995) mostra em seu trabalho, quando aponta que as convicções e atitudes fazem com que as pessoas assumam posturas extremamente defensivas, como, por exemplo, negar as posturas machistas hoje, na contemporaneidade, dizendo que as mulheres são livres e podem estudar e trabalhar, embora no trabalho elas sempre ganhem menos do que os homens para o mesmo tipo de função.

É importante chamar a atenção para o fato de que toda essa discriminação ou uma maior exclusão não parecem de imediato promover alterações significativas, uma vez que, mesmo com todos os aspectos considerados, as mulheres afirmaram que, se tivessem que escolher o seu sexo, escolheriam ser mulher. Nos 114 questionários respondidos, apenas 9 mulheres disseram que "preferiam ser homem", isto é, apenas $8 \%$ da população alvo. Isso aparece através dos depoimentos, em que são expressos elementos significativos da feminilidade, tais como:

\footnotetext{
a. Não tenho o que reclamar do meu sexo.

b. A mulher é tudo de bom.

c. Porque é uma maravilha ser mulher.

d. Só a mulher pode gerar filhos.
} 
e. Ser mulher foi obra divina de termos oportunidades de fazer várias coisas, por exemplo, ser mãe.

Os dois últimos depoimentos estão voltados para a maternidade, evidenciando como isto ainda encontra-se muito forte nas concepções de vida das mulheres, resultado de processos internalizados que geram o desejo de ser mãe, não necessariamente pelo desejo de ter uma filha ou filho, mas muito mais pela visão de que este seria o papel do sexo feminino.

Isso é tão nítido, que em pesquisa desenvolvida por Santos (1990) ${ }^{11}$, junto a um público da terceira idade, em relação à aposentadoria para homens e mulheres, os primeiros tendiam a ficar tristes e entrar em crise identitária, enquanto as segundas assimilavam muito bem a aposentadoria, como uma chance de resgatar a família e os cuidados da casa - outrora relegados a segundo plano -, mesmo que fosse como avós. $O$ que mostra que a identidade feminina ainda se encontra enraizada com princípios antigos da mulher mãe e dona-de-casa; a tal ponto que ela não é rompida quando a mulher passa a trabalhar no espaço público, mas apenas é postergada para um segundo momento - o da aposentadoria.

Percebe-se que os antigos atributos ligados às características de fragilidade, docilidade, meiguice é que continuam prevalecendo para a identidade feminina. Embora já se possam constatar algumas pequenas mudanças, já que, em meio a todas as características que surgem na pesquisa sobre o "ser mulher", três fogem aos antigos valores: idealista, batalhadora e inteligente.

Assim, tomando-se Lepre como ponto de intercessão, nota-se que:

A construção da identidade é social e acontece durante toda, ou grande parte, da vida dos indivíduos. Desde o seu nascimento o homem [e a mulher] inicia uma longa e perene interação com o meio em que está inserido [a], a partir da qual construirá não só a sua identidade, como a sua inteligência, suas emoções, seus medos, sua personalidade. [...] A construção da identidade é um desses fatores relacionados ao desenvolvimento que tem íntima, senão total, dependência da cultura e da sociedade onde o indivíduo está inserido (2003/2004, p. 1).

\footnotetext{
${ }^{11}$ Trabalho desenvolvido por Fátima Santos, com o título Identidade e Aposentadoria, 1990.
} 
Diante de tudo o que foi exposto, consideram-se como significativas as dificuldades enfrentadas por parte das mulheres das classes populares para atingir sua autonomia, em direção à plena vivência do processo da cidadania ativa. Entre mudanças, avanços e recuos, terminam ainda prevalecendo antigos conceitos internalizados pelas mulheres, que ora reconhecem os seus direitos, ora afirmam que as coisas acontecem porque a sociedade é machista.

\section{Considerações finais}

Entendemos que mulheres e homens, ao longo da história da humanidade, sempre foram pautados por características que implicam em desigualdade e segmentação das relações entre os mesmos, diante de papéis socialmente atribuídos a cada um dos sexos. São, portanto, comportamentos construídos e internalizados que mulheres e homens manifestam no âmbito da sociedade, como mostram os dados da pesquisa.

Percebemos, na compreensão das mulheres sobre a cidadania, concepções de submissão e dependência, de discriminações e exclusões, mesmo quando elas já reconhecem seus direitos. Assim, ao mesmo tempo em que apontam os direitos vinculados à cidadania, chamam a atenção para a falta de sua vivência no espaço social, evidenciando em nosso entender processos já internalizados, isto é, "culturalmente vivenciados no espaço de vida".

No momento, o contexto das mulheres voltado para a cidadania ativa, mesmo com todo o seu avanço, continua apresentando algumas lacunas significativas, diante de uma sociedade e de uma cultura ainda patriarcais e androcêntricas; e em face da ausência de políticas públicas voltadas para o universo feminino. Neste contexto, percebemos que em seu conjunto as mulheres do universo pesquisado estão inseridas em múltiplas exclusões, não apenas de gênero, mas também de classe.

Partindo do estudo da cidadania, podemos aprofundar tal entendimento no contexto de gênero, a partir da percepção de ser mulher. No tema percepção de ser mulher, em várias etapas da pesquisa elas expressaram que ser mulher é algo bom ou 
ótimo, todavia, por outro lado, reconhecem a existência de fortes diferenças entre elas e os homens, na medida em que são mais discriminadas e excluídas do que o sexo masculino.

Esses aspectos nos levaram a perceber que, embora entendendo e vivenciando transformações, as mulheres ainda se encontram presas a antigos valores discriminatórios, decorrentes da sociedade machista. No caso do grupo pesquisado, composto por alunas do último ano do Ensino Médio, constatamos também que a maior escolaridade não contribuiu para mudar esse quadro, o que pode ser atribuído à baixa qualidade da educação recebida.

Por exemplo, mesmo quando trabalham fora as mulheres são cobradas para as atividades domésticas, sejam os cuidados com a casa ou com as crianças - irmãs(os) menores ou filhas(os) -, oscilando entre o moderno e o tradicional. Os depoimentos, tanto no questionário quanto nas entrevistas, mostram que o homem tudo pode e está fora de maiores responsabilidades perante as mulheres.

Nesse sentido, entre as características femininas citadas pelo grupo, percebemos a predominância dos antigos papéis atribuídos à mulher. Elas citaram atributos como educada, mãe, fiel, carinhosa, dedicada, dona-de-casa, sincera, companheira, compreensiva, amiga, romântica, frágil, responsável, sensível, vaidosa, para apenas uma menção de "ser forte", qualidade que aparece em último lugar. Isso evidencia, a nosso ver, a reprodução da discriminação de gênero, uma vez que tais qualidades não foram vistas por elas em relação ao sexo masculino.

Mulheres e homens forjados nessas concepções tendem a reproduzi-las nas gerações subsequentes, limitando os espaços das mulheres, as quais, mesmo com maior escolaridade e trabalhando no espaço público - como era a situação de 50\% das mulheres participantes das entrevistas -, estão ocupadas em atividades precárias e limitadas, como mostram os salários recebidos, cuja média ficava abaixo do salário mínimo.

Entretanto, o estudo da cidadania destas mesmas mulheres trouxe à tona aspectos significativos, ao revelar a existência de novas concepções, entre as quais se incluem: direitos, educação, igualdade, participação, respeito e responsabilidade. Embora, neste momento, elas existam apenas no discurso, na fala, no ver, no querer, isto 
já é um caminho para outras transformações emancipatórias que se fazem necessárias para a vivência plena da cidadania ativa por parte das mulheres das classes populares.

É importante ressaltar que as mulheres têm a noção de cidadania, mas admitem a necessidade de que ocorram mudanças de atitudes e comportamentos na sociedade, principalmente no universo masculino, para que essa cidadania seja efetivada no cotidiano.

$\mathrm{Na}$ verdade, são estereótipos e preconceitos sobre os universos feminino e masculino, socialmente construídos ao longo dos anos, que implicam comportamentos dissociáveis e confusos nas relações entre os seres humanos. Embora reconheçam os limites, discriminações e desrespeito sentidos por conta do machismo, que elas apontaram, ainda não se percebem como sendo elas próprias que podem mudar isto na prática, pois, uma vez instalado, o preconceito fica incorporado no imaginário social e na compreensão pessoal e interna das mulheres e em suas representações.

Nesse contexto, faz-se necessário ainda adentrar no estudo das políticas públicas de gênero, de forma a possibilitar a abertura de espaços para a construção integrada de novas relações sociais para o conjunto da sociedade, uma vez que não se concebe o estudo de gênero separado do todo, diante das políticas e ideologias que contribuem para a reprodução do processo de alienação e exclusão social. Assim, pensamos em ações que coloquem a discussão de gênero na ordem do dia, nas políticas públicas como um todo, e em específico na política social da educação, campo para a promoção do crescimento e desenvolvimento dos seres humanos e sociais, de forma a promover transformações consistentes.

Diante de tudo isso, pode-se dizer que a representação da cidadania feminina aqui em específico, mas também a dos homens - incorpora os comportamentos que foram e são traçados ao longo da história da humanidade e reforçados pela educação. Além do que, as mulheres das classes populares têm pouca ou quase nenhuma visibilidade, mobilidade e participação no campo político, social e familiar, encontrandose ausentes das instâncias decisórias e ideológicas para a efetivação e elaboração de políticas públicas no contexto de gênero. 
Voltamos a ressaltar que esse processo no Brasil é decorrente tanto da divisão social em classes, que priva a maioria da população das classes populares do acesso, participação e vivência de seus direitos, quanto da cultura nitidamente patriarcal e androcêntrica, que ainda não perdeu toda a sua força, mas apenas viabiliza-se na prática por meio de novos arranjos.

\section{Referências Bibliográficas}

AUAD, Daniela. Educar meninas e meninos: relações de gênero na escola. São Paulo: Contexto, 2006.

BENEVIDES, Maria Victória. A cidadania ativa: referendo, plebiscito e iniciativas populares. São Paulo: Ática., 1991.

BENEVIDES, Maria Victória. Cidadania e democracia. Lua Nova, São Paulo, n. 32, p. 5-16, 1994.

BENEVIDES, Maria Victória. Democracia de iguais, mas diferentes. In: BORBA, A. et al. Mulher e política: gênero e feminismo no Partido dos Trabalhadores. São Paulo: Fundação Perseu Abramo, 1998.

BERQUÓ, Elza. Arranjos familiares no Brasil:uma visão demográfica. In Schwarck, L.M. Contraste da Identidade Contemporânea. História da vida privada no Brasil 4. São Paulo: Companhia das Letras, 1998.

BOURDIEU, Pierre. A dominação masculina. Rio de Janeiro: Bertrand Brasil, 1999.

BRASIL. Constituição da República Federativa do Brasil. Texto promulgado em 05 de outubro de 1988. Disponível em: <http://www.planalto.gov.br/ccivil-3/constituição\%C3\%/ A7ao.htm>. Acesso em: 07 jun. 2004.

BRASIL. Lei n 10.406, de 10 de janeiro de 2002. Código Civil. Disponível em: <http://www.mj.gov.br/sal/código_civil/indice-htm>. Acesso em: 08 jun. 2004.

CASTELLS, Manuel. O Poder da Identidade. Vol.2. São Paulo: Paz e terra,1999 
CHAUI, Marilena. Repressão sexual: essa nossa (des) conhecida. 3. ed. São Paulo: Brasiliense, 1984.

CHAVES, Jaqueline. Ficar com: um estudo sobre o novo código de relacionamento no Brasil. Rio de Janeiro: Revan, 1997.

FREYRE, Gyberto. Casa-grande e senzala. Brasília: Editora UnB, 1963.

FURTADO, Celson. O Longo amanhecer. Reflexões sobre a formação do Brasil. São Paulo: Paz e Terra, 1999.

FUNDAÇÃO PERSEU ABRAMO. A situação da mulher brasileira no espaço público e privado. São Paulo, 2001. Disponível em: <http://www.fpabramo.org.br/>. Acesso em: 18 jul. 2004.

FUNDAÇÃO PERSEU ABRAMO. Mulheres brasileiras e gênero nos espaços público e privado: uma década de mudança na opinião pública. São Paulo: Fundação Perceu ABRAMO, 2013.

GIBRAM, Namara; PAZ, Maria das Graças. Trabalho e família: um panorama da realidade brasileira. . In: GALINKIN, Ana Lúcia e SANTOS, Caludiene (Org.). Gênero e psicologia social: interfaces. Brasília, 2010.

JODELET, Denise. Análise Psicossocial e Ética da Exclusão. In. SAWAIA, Bader. (org.). As artimanhas da Exclusão: Análise Psicossocial e Ética da Desigualdade Social. Petrópolis: Vozes, 1999. 999.

LEPRE, Rita. Adolescência e Construção da Identidade. São Paulo, 2003. Disponível em: < http://www.psicopedagogia.com.br/artigos/artigo.asp?entrID=395>. Acesso em: 20 jun. 2004 .

LIPMAN, Matthew. O pensar na educação. 3. ed. Petrópolis: Vozes, 1995.

MADUREIRA, Ana Flávia. Gênero, sexualidade e processos indenitários na sociedade brasileira: tradição e modernidade em conflitos. In: GALINKIN, Ana Lúcia e SANTOS, Caludiene (Org.). Gênero e psicologia social: interfaces.Brasília, 2010.

MELUCI, Alberto. A invenção do presente: movimentos sociais nas sociedades complexas. Petrópolis: Vozes, 2001.

MENEZES, Walfrido. A barriga cresceu... adeus meninas! exclusão social: do real ao simbólico na gravidez adolescente. João Pessoa: Idéia, 2002. 
MENEZES, Walfrido. Era...uma vez: mulheres (in)visíveis:m estudo da representação social acerca da cidadania feminina. São Paulo: IGU Editora, 2011.

MORENO, Montserrat. Como se ensina a ser menina na escola: o sexismo na escola. Rio de Janeiro: Moderna, 1999.

MÉZÀROS, István. O poder da ideologia. São Paulo: Boitempo, 2004.

NASCIMENTO, Elimar. Hipóteses sobre a nova exclusão social: dos excluídos necessários aos excluídos desnecessários. Caderno CRH, Salvador, n. 21, p. 29-47, jul./dez. 1994.

NEDER, Gizlene. Ajustando o Foco das lentes: Um Novo Olhar Sobre a Organização das famílias no Brasil. In. KALOVSTIAN, Silvio (org.). Família Brasileira, a Base de Tudo. São Paulo: Cortez/Brasilia: UNICEF,1998.

OLIVEIRA, Francisco. O que é formação para a cidadania? entrevista concedida a Silvio Caccia Bava. São Paulo: Instituto Pólis, 1999. Disponível em:

<www.dhnet.org.br/direitos/sos/textos/oliveira.htm>. Acesso em: 12 ago. 2005 .

ROSEMBERG, Fúlvia. Educação formal, mulher e gênero no Brasil contemporâneo. Estudos Feministas, Florianópolis, v. 9, n. 2, p. 515-540, 2001. Disponível em: <http://www.scielo.br/sciel.php?script=sci_arttex\&pid=S0104-026X2001000200011>. Acesso em: 12 nov. 2004.

ROSEMBERG, Fúlvia. A educação de mulheres jovens e adultas no Brasil. In: SAFFIOTI, Heleieth.; MUÑOZ-VARGAS, Monica. (Orgs.). Mulher brasileira é assim. Rio de Janeiro: Rosa dos Tempos, 1994. p. 27-62.

SAFFIOTI, Heleieth. Rearticulando Gênero e Classes Sociais. In: 140 ENCONTRO da ANPOCS. 140, 1992. Anais.Caxambu: ANPOCS, 1992. P.1-48.

SAFFIOTI, Heleieth. Gênero, patriarcado, violência. São Paulo: Fundação Perseu Abramo, 2004.

SAFFIOTI, Heleieth ; MUÑOZ-VARGAS, M. Posfácio: conceituando gênero. In: SAFFIOTI, Heleieth ; MUÑOZ-VARGAS, Monica. Mulher brasileira é assim. Rio de Janeiro: Rosa dos Tempos, 1994. p. 271-283.

SANTOS, Fátima. Identidade e Aposentadoria. Recife: editra Universitária UFPE, 1990.

SCOTT, Parry e CORDEIRO, Rosineide Maira. Mulheres no campo: polarização de gênero e sinais de ascensão. In: VENTURI, Gustavo; GODINHO, Tatau (Org.). Mulheres brasileiras e gênero nos espaços públicos e privados: uma década de mudanças na opinião pública. 
São Paulo: Editora Fundação Perseu ABRAMO, 2013.

STREY, Marlene Neves. Gênero. In: JACQUES, Maria das Graças; STREY, Marlene Neves;

GUARESCHI, Pedrinho Arcides, et al. Psicologia social contemporânea. Petrópolis: Vozes, 2011.

SPOSATI, Aldaíza. et al. Os mínimos sociais e seguridade social: uma revolução na consciência da cidadania. Rio de Janeiro, 1997.

TAVARES, Celma; BUARQUE, Cristina et al. Mulheres construindo a igualdade: caderno etnicorracial. Recife: secretaria da mulher, 2011.

XIBERRAS, M. Les Théories de L'exclusion. Paris: Armand Colin, 1996.

Recebido em: 20/09/2013

Aprovado em: 21/11/2013

Universidade do Estado de Santa Catarina - UDESC

Centro de Ciências Humanas e da Educação - FAED

Revista PerCursos

Volume 14 - Número 27 - Ano 2013

revistapercursos@gmail.com 